\title{
A Prospective Cohort Study of Treatment Decision-Making for Prostate Cancer following Participation in a Multidisciplinary Clinic
}

Lauren M. Hurwitz, MHS ${ }^{\mathrm{a}, \mathrm{b}}$; Jennifer Cullen, PhD, MPH ${ }^{\mathrm{a}, \mathrm{b}, \mathrm{c}}$; Sally Elsamanoudi, $\mathrm{MPH}^{\mathrm{a}, \mathrm{b}, \mathrm{d}}$; Daniel J. Kim, $\mathrm{MD}^{\mathrm{d}}$; Jane Hudak, PhD, RN ${ }^{\mathrm{d}}$; Maryellen Colston, $\mathrm{RN}^{\mathrm{d}}$; Judith Travis, $\mathrm{RN}^{\mathrm{d}}$; Huai-Ching Kuo, MS ${ }^{\mathrm{a}, \mathrm{b}}$;

Christopher R. Porter, MD, FACS ${ }^{\mathrm{a}, \mathrm{e}}$; Inger L. Rosner, MD ${ }^{\mathrm{a}, \mathrm{d}}$

${ }^{a}$ Center for Prostate Disease Research, Department of Defense; 1530 E. Jefferson St., Rockville, Maryland, United States

${ }^{b}$ Henry M. Jackson Foundation for the Advancement of Military Medicine; 6720A Rockledge Dr \#100, Bethesda, Maryland, United States

${ }^{c}$ Uniformed Services University of the Health Sciences, Department of Surgery; 4301 Jones Bridge Road, Bethesda, Maryland, United States

${ }^{\mathrm{d}}$ Walter Reed National Military Medical Center, Department of Urology; 8901 Wisconsin Ave, Bethesda, Maryland, United States

${ }^{e}$ Virginia Mason Medical Center, Department of Urology; 1100 Ninth Ave, Seattle, Washington, United States

\section{Correspondence and request for reprints:}

Inger L. Rosner, MD

Associate Director, Center for Prostate Disease Research

8901 Wisconsin Ave

Bethesda, MD 20889

Phone: 301-295-4270

Fax: 301-295-4280

inger.1.rosner.mil@mail.mil

Manuscript type: Original Article

Running head: Prostate Cancer Decision-Making

Keywords: Decision-making, multidisciplinary clinic, patient preferences, prostate cancer, treatment

\section{Word Count:}

Abstract: 256

Main Text: 2,494

Funding: This research was funded through the Center for Prostate Disease Research and Uniformed Services University of the Health Sciences (HU0001-10-2-0002). 


\begin{abstract}
:
Background: Patients diagnosed with prostate cancer $(\mathrm{PCa})$ are presented with several treatment options of similar efficacy but varying side effects. Understanding how and why patients make their treatment decisions, as well as the effect of treatment choice on long-term outcomes, is critical to ensuring effective, patient-centered care. This study examined treatment decision-making in a racially diverse, equal-access, contemporary cohort of PCa patients counseled on treatment options at a multidisciplinary clinic.

Methods: A prospective cohort study was initiated at the Walter Reed National Military Medical Center (formerly Walter Reed Army Medical Center) in 2006. Newly diagnosed PCa patients were enrolled prior to attending a multidisciplinary clinic. Patients completed surveys pre- and post-clinic to assess treatment preferences, reasons for treatment choice, and decisional regret.

Results: As of January 2014, 925 PCa patients were enrolled in this study. Surgery (54\%), external radiation $(20 \%)$, and active surveillance (12\%) were the most common primary treatments for patients with low- and intermediate-risk PCa, while high-risk patients chose surgery (34\%) or external radiation with neoadjuvant hormones (57\%). Treatment choice differed by age at diagnosis, race, comorbidity status, and calendar year in both univariable and multivariable analyses. Patients preferred to play an active role in the decision-making process and cited doctors at the clinic as the most helpful source of treatment-related information. Almost all patients reported satisfaction with their decision.

Conclusions: This is one of the first prospective cohort studies to examine treatment decision-making in an equal-access, multidisciplinary clinic setting. Studies of this cohort will aid in understanding and improving the $\mathrm{PCa}$ decision-making process.
\end{abstract}




\section{Introduction}

In 2015, an estimated 220,800 men will be diagnosed with prostate cancer (PCa) in the US [1]. Subsequent to diagnosis, which alone can be stressful and upsetting, these patients will have to make a difficult decision on how to treat their cancer. Common primary treatment options for PCa include radical prostatectomy (open, laparoscopic, or robotic), external beam radiation therapy (conformal or intensity modulated) with or without androgen deprivation therapy, and brachytherapy. In recent years, active surveillance has also gained acceptance as a safe and viable alternative to immediate curative therapy for patients with favorable clinical characteristics [2, 3].

Since evidence to support the preferential use of any one of these treatments is limited [4], treatment decisions are instead often based on physician recommendations and individual patient preferences. Patients and their doctors may consider tumor characteristics, patient age, comorbidity and overall physical health, as well as the unique risks and side effects that accompany each therapy [5-9]. Patients may also draw upon treatment advice from family, friends, and various media resources. Combining these sources of information is a complex endeavor, yet few large-scale studies have examined how such factors interplay and inform the decision-making process.

Prior studies have found that most newly-diagnosed PCa patients prefer [10], and report playing [11], an active or collaborative role in treatment decision-making. Decision aids have been developed to help patients navigate the process, but systematic reviews have concluded that these aids vary widely in content and do not meet International Patient Decision Aid Standards [12, 13]. Moreover, only 35.5\% of urologists and radiation oncologists currently report using decision aids in their clinics [14]. Other studies have shown that variation in treatment decisions may be due to variation in information received as opposed to personal preferences [5], and that there may be racial/cultural differences in how patients arrive at their decisions [15].

In an effort to better understand how and why newly diagnosed PCa patients make treatment decisions, as well as subsequent decisional regret and quality of life, a prospective cohort study was initiated in 2006 at the Walter Reed National Military Medical Center (formerly Walter Reed Army 
Medical Center). This racially diverse cohort is particularly suited to explore treatment decision-making because all patients within the cohort had equal access to healthcare, and all patients participated in a multidisciplinary clinic with a wide scope of specialists to discuss treatment options for their cancer. The current paper is descriptive in nature and aims to describe (1) the design of this study, (2) baseline characteristics and decision-making preferences of the cohort, and (3) treatment patterns and sociodemographic predictors of treatment choice. Results pertaining to regret and quality of life will be detailed in a subsequent manuscript. 


\section{Methods}

\subsection{Study Population}

The study population consisted of patients presenting to the Center for Prostate Disease Research (CPDR) at the Walter Reed National Military Medical Center (WRNMMC) in Bethesda, Maryland, for treatment of newly diagnosed, non-metastatic PCa. All enrolled patients provided informed consent to participate in the decision-making study; a subset of patients also consented to participate in a separate health-related quality of life (HRQoL) study. Both prospective cohort studies received institutional review board approval at WRNMMC. Enrollment began in June 2006 and is ongoing.

All enrolled patients attended a WRNMMC multidisciplinary clinic to discuss their treatment options. At this clinic, patients met individually with a urologic oncologist, radiation oncologist, andrologist, psychologist, and nurse educator, as described previously [16].

\subsection{Data Collection and Survey Instruments}

\subsubsection{Pre-Clinic}

Before attending the multidisciplinary clinic, patients completed a demographic questionnaire as well as a 12-item pre-clinic questionnaire. The pre-clinic questionnaire asked about current preferences for treatment and included the Control Preferences Scale (CPS), a validated instrument that measures the degree of control an individual wants to assume over medical treatment decisions [17]. Clinical data, including clinical stage, Gleason sum, and diagnostic PSA, were abstracted from patient medical records.

\subsubsection{Post-Clinic}

At the conclusion of the clinic, patients met with a research coordinator to complete the appropriate version of the post-clinic questionnaire: either the "decision made" questionnaire for those who made a treatment decision at the clinic, or the "decision pending" questionnaire for those who had not yet made a treatment decision. The "decision pending" questionnaire asked patients to specify which treatments the physicians recommended, and which treatments they were leaning towards or against. The 
"decision made" questionnaire included the same items as well as additional items to assess the information that helped patients reach their treatment decisions. Both versions of the post-clinic questionnaire included the CPS and the Satisfaction with Decision Scale, a 6-item instrument with established reliability and validity that measures global satisfaction with a decision [18]. Following the multidisciplinary clinic, the urologic oncologist and radiation oncologist also completed questionnaires to rate patient candidacy for each treatment.

\subsubsection{One Month Follow-Up}

Telephone interviews were conducted one month following the multidisciplinary clinic. Patients who filled out the "decision made" questionnaire at the clinic were asked to confirm their treatment decision. Patients who filled out the "decision pending" questionnaire were asked whether they had since made a treatment decision. If the patient remained undecided, the telephone interview was concluded and repeated at one month intervals, for up to six months or until the patient reached a decision. Once the patient reported a treatment decision, he was asked about the information that helped him reach that decision.

\subsubsection{Decisional Regret and Health-Related Quality of Life}

The Decision Regret Scale (DRS) was mailed to patients at 6, 12, 24, and 36 months following the end of primary treatment. The DRS is a validated 5-item instrument that measures distress or remorse after a health care decision [19].

For the subset of patients who consented to participate in the HRQOL study, HRQoL data were captured using two validated questionnaires: the Expanded Prostate Cancer Index Composite, and the 36item RAND Medical Outcomes Study Short Form [20-22]. These questionnaires were administered at baseline (prior to treatment), 3, 6, 9, 12, 18, 24, 30, and 36 months, and then annually for up to ten years following the initial biopsy. Regret and HRQoL results, with the exception of baseline HRQoL, are not reported in this manuscript.

\subsection{Statistical Analysis}


Summary statistics, counts, and percents were used to describe the baseline characteristics of the cohort, primary treatments received, and patient preferences. Primary treatment was defined as treatment received within 12 months of PCa diagnosis. Patients who chose to delay therapy for at least 12 months were categorized as active surveillance if they had National Comprehensive Cancer Network (NCCN) low- or intermediate-risk PCa and a life expectancy of at least 10 years (i.e. $\leq 75$ years old, according to actuarial life tables) and watchful waiting if they had high-risk PCa or were $>75$ years old.

Predictors of treatment choice were examined through analyses stratified by NCCN risk stratum (low/intermediate risk and high risk). For low- and intermediate-risk patients undergoing surgery, EBRT, or active surveillance, sociodemographic factors were compared across treatment groups using ANOVA and chi-square tests. Multinomial logistic regression, with primary treatment as the outcome, was used to test whether sociodemographic variables were independent predictors of treatment choice. For high-risk patients undergoing surgery or EBRT with neoadjuvant hormone therapy, t-tests, chi-square tests, Cochran-Armitage trend tests, and logistic regression were used to test for differences in sociodemographic factors between treatment groups. Regression models included age, race, education, marital status, family history, comorbidity status, and calendar year as covariates. All statistical tests were two-sided, and p-values $<0.05$ were considered statistically significant. Analyses were conducted using SAS 9.3 (SAS Institute Inc., Cary, NC, USA). 


\section{Results}

\subsection{Baseline Characteristics}

Between June 2006 and January 2014, 73\% of PCa patients attending the CPDR WRNMMC multidisciplinary clinic enrolled in the study, yielding a sample size of 925 patients. The study cohort consisted primarily of retired servicemen from all branches of the military (Table 1). Mean age at diagnosis was 61 years old. Most men were married (86\%) and more than half had an advanced academic degree (52\%). The racial breakdown was 59\% Caucasian, 36\% African-American, and 5\% other. Fiftyeight percent of men were diagnosed with very low or low-risk PCa, $31 \%$ were diagnosed with intermediate-risk PCa, and $11 \%$ were diagnosed with high-risk PCa according to NCCN criteria (Table 2). Upon entry into the study, $17 \%$ of men reported having a major comorbidity (heart disease/CVD, lung disease/COPD, and/or stroke). HRQoL data were available for 795 patients ( $86 \%$ of the study cohort); analysis of these patients revealed that their pre-treatment HRQoL was comparable to that of the general population (Supplementary Table 1).

\subsection{Patient Preferences and Effect of Multidisciplinary Counseling}

The majority of patients $(68 \%)$ preferred to play an active role in the treatment decision-making process, $29 \%$ preferred collaborative decision-making with the doctor, and $4 \%$ preferred to play a passive role, according to the Control Preferences Scale (Figure 2). Patients' thoughts on each treatment changed over the course of the clinic, with fewer patients reporting uncertainty and more leaning towards or against each treatment post-clinic (Figure 3). Sixty-two percent of patients reported a preference for a particular treatment prior to clinic, and $64 \%$ of patients had decided on a treatment by the end of the clinic. Of the men who made a treatment decision at the clinic, $6 \%$ changed their decision one month later. Of the men who did not make a treatment decision at the clinic, $84 \%$ made a decision by one month. Nearly all patients (98\%) who made a treatment decision expressed satisfaction with their decision at post-clinic and one-month follow-up. 


\subsection{Predictors of Treatment Choice}

The primary treatments received, overall and by NCCN risk stratum, are shown in Table 3. Among the low- and intermediate-risk patients, there were statistically significant differences in sociodemographic factors across the major primary treatment groups (Table 4). Patients undergoing surgery were younger and more likely to report a family history of PCa. Patients undergoing EBRT tended to be older, African-American, and have a major comorbidity. The use of active surveillance increased significantly since study onset in 2006. After multivariable adjustment, age $(p<0.0001)$, race ( $p<0.0001)$, comorbidity status $(p=0.02)$, and calendar year $(p<0.0001)$ remained significant, independent predictors of treatment choice.

Few differences were observed among high-risk patients undergoing surgery or EBRT with neoadjuvant hormone therapy (Table 5). In the multivariable model, only age $(p<0.0001)$ and education $(p=0.05)$ were significantly associated with treatment choice, with older patients and those with a high school education skewing towards EBRT. A greater proportion of African-Americans chose EBRT as compared to Caucasians, but this difference was not statistically significant in univariable or multivariable analysis.

\subsection{Sources of Information}

When asked to select one or more sources of information that were most helpful in making their decision, $87 \%$ of patients selected doctors from the CPDR (Table 6). Other common sources of information included reading materials (40\%), comments from a wife/significant other (33\%), and the internet (30\%). Patients electing surgery or radiation (EBRT or brachytherapy) were also asked to select one or more reasons why they chose that treatment option; responses are displayed in Supplementary Tables $2 \& 3$. 


\section{Discussion}

This study is one of the first prospective cohort studies to examine PCa treatment decisionmaking within the context of a multidisciplinary urology clinic. It is important to study treatment patterns in this setting, since patients attending these clinics are less likely to be influenced by physician bias, or the tendency of physicians to recommend treatments within their specialty [23]. Treatment patterns of patients attending multidisciplinary clinics have been found to differ from those who consult with individual practitioners $[24,25]$. This study has the added benefit of representing an equal-access healthcare system, thereby reducing confounding due to varying levels of healthcare access.

The treatment patterns of low- and intermediate-risk PCa patients in this cohort are consistent with previous studies. Other studies have reported that patients undergoing surgery are younger and healthier than those choosing EBRT $[6,7,26]$. Prior studies have also shown that African-Americans are

more likely to choose EBRT over surgery [27, 28]. The present study confirms that this racial difference holds in an equal-access cohort with counseling via a multidisciplinary clinic, where differences are less likely to be caused by differential access to care or knowledge, and more likely to reflect true differences in underlying patient preferences.

Interestingly, race was not associated with treatment choice among high-risk patients in this study. Race was also not associated with receipt of definitive therapy among high-risk patients (data not shown), as almost all high-risk patients (94\%) received definitive therapy. Previous studies utilizing SEER data have shown that African-American men with high-risk PCa are less likely to receive definitive treatment than Caucasians [29] and that the disparity is reduced among insured men [30]. Though the number of high-risk patients in the current study is small, their high rate of definitive treatment suggests that improved access to care combined with multidisciplinary counseling may further reduce this racial disparity and prevent undertreatment of men with high-risk disease.

Consistent with previous studies, almost all men in this cohort (97\%) preferred to play an active or collaborative role in treatment decision-making $[10,11]$. The multidisciplinary clinic appeared 
effective at facilitating decision-making, as patient preferences regarding each treatment shifted over the course of the clinic, almost two thirds of patients left the clinic having reached a decision, and the vast majority cited doctors at the CPDR as the most helpful source of treatment-related information. Patient satisfaction with the treatment decision was also extremely high. As other resources such as decision aids have shown limited utility in increasing patient knowledge and promoting shared decision-making [12, 13], the multidisciplinary clinic may be an important means for patients to achieve their desired role in the decision-making process.

Other study strengths include the prospective study design, the racial diversity of the cohort, and the completeness of the data. Moreover, great care was taken to differentiate patients on active surveillance from those on watchful waiting. As these management strategies are often conflated, this study utilized strict, user-defined definitions to distinguish these groups. Use of these definitions helped to more accurately classify patients into treatment categories, though some misclassification may have still occurred.

This was a single-institution study of a military population, and as a result generalizability may be limited. Generalizability may also be limited due to the high level of educational attainment of the cohort. Fifty-two percent of patients in this study earned a master's or doctoral degree; data from the National Census Bureau indicate that the percentage for males is only $11 \%$ nationwide [31]. As education level may influence a patient's decision-making preferences [5], the study results should be applied to populations with differing distributions of educational attainment with caution. Furthermore, the study did not collect information on reasons for choosing active surveillance, as active surveillance was not commonly utilized when this study began in 2006. Use of active surveillance has since increased, both in our study population (11\% of the cohort in 2006 vs. 21\% in 2013) and nationwide [32, 33]. A future analysis will report in greater detail on the shifting demographics, preferences, and outcomes of our active surveillance group.

Additional studies will be conducted within this cohort to examine decisional regret as a result of the primary treatment decision. Regret will be compared across treatment group, and changes in regret 
will be examined in relation to both PCa-specific and general HRQoL. Together, these studies will provide a detailed, longitudinal understanding of PCa treatment decision-making, from initial clinic visits to long-term clinical and patient-reported outcomes. Such knowledge will help to improve the decisionmaking process and ensure patient-centered care that optimizes cancer outcomes, patient satisfaction, and quality of life. 


\section{References}

[1] Society AC. Cancer Facts \& Figures 2015. Atlanta: American Cancer Society; 2015.

[2] Dall'Era MA, Albertsen PC, Bangma C, Carroll PR, Carter HB, Cooperberg MR, et al. Active surveillance for prostate cancer: a systematic review of the literature. Eur Urol. 2012;62:976-83. doi:

10.1016/j.eururo.2012.05.072. Epub Jun 7.

[3] Ritch CR, Graves AJ, Keegan KA, Ni S, Bassett JC, Chang SS, et al. Increasing use of observation among men at low risk for prostate cancer mortality. J Urol. 2014;4:04357-2.

[4] Sun F, Oyesanmi O, Fontanarosa J, Reston J, Guzzo T, Schoelles K. Therapies for Clinically Localized Prostate Cancer: Update of a 2008 Systematic Review. AHRQ Comparative Effectiveness Reviews. Rockville, MD: Agency for Healthcare Research and Quality; 2014.

[5] Zeliadt SB, Ramsey SD, Penson DF, Hall IJ, Ekwueme DU, Stroud L, et al. Why do men choose one treatment over another?: a review of patient decision making for localized prostate cancer. Cancer. 2006;106:1865-74.

[6] Sommers BD, Beard CJ, D'Amico AV, Kaplan I, Richie JP, Zeckhauser RJ. Predictors of patient preferences and treatment choices for localized prostate cancer. Cancer. 2008;113:2058-67. doi: 10.1002/cncr.23807.

[7] Ihrig A, Keller M, Hartmann M, Debus J, Pfitzenmaier J, Hadaschik B, et al. Treatment decision-making in localized prostate cancer: why patients chose either radical prostatectomy or external beam radiation therapy. BJU Int. 2011;108:1274-8. doi: 10.111/j.464-410X.2011.10082.x. Epub 2011 Mar 16.

[8] Sidana A, Hernandez DJ, Feng Z, Partin AW, Trock BJ, Saha S, et al. Treatment decision-making for localized prostate cancer: what younger men choose and why. Prostate. 2012;72:58-64. doi: 10.1002/pros.21406. Epub 2011 Apr 25.

[9] Daskivich TJ, Lai J, Dick AW, Setodji CM, Hanley JM, Litwin MS, et al. Variation in treatment associated with life expectancy in a population-based cohort of men with early-stage prostate cancer. Cancer. 2014;17:28926.

[10] Davison BJ, Breckon EN. Impact of health information-seeking behavior and personal factors on preferred role in treatment decision making in men with newly diagnosed prostate cancer. Cancer Nurs. 2012;35:411-8. doi: 10.1097/NCC.0b013e318236565a.

[11] Song L, Chen RC, Bensen JT, Knafl GJ, Nielsen ME, Farnan L, et al. Who makes the decision regarding the treatment of clinically localized prostate cancer--the patient or physician?: results from a population-based study. Cancer. 2013;119:421-8. doi: 10.1002/cncr.27738. Epub 2012 Jul 11. [12] Adsul P, Wray R, Spradling K, Darwish O, Weaver N, Siddiqui S. Systematic Review of Decision Aids for Newly Diagnosed Prostate Cancer Patients Making Treatment Decisions. J Urol. 2015;5:04115-4.

[13] Violette PD, Agoritsas T, Alexander P, Riikonen J, Santti H, Agarwal A, et al. Decision aids for localized prostate cancer treatment choice: Systematic review and meta-analysis. CA Cancer J Clin. 2015;12:21272.

[14] Wang EH, Gross CP, Tilburt JC, Yu JB, Nguyen PL, Smaldone MC, et al. Shared decision making and use of decision AIDS for localized prostate cancer : perceptions from radiation oncologists and urologists. JAMA Intern Med. 2015;175:792-9. doi: 10.1001/jamainternmed.2015.63.

[15] Wagner SE, Drake BF, Elder K, Hebert JR. Social and clinical predictors of prostate cancer treatment decisions among men in South Carolina. Cancer Causes Control. 2011;22:1597-606. doi: 10.007/s10552011-9836-2. Epub 2011 Aug 30.

[16] Hudak JL, McLeod DG, Brassell SA, Gant DA, Shaar S, Hudak RP, et al. The design and implementation of a multidisciplinary prostate cancer clinic. Urol Nurs. 2007;27:491-8.

[17] Degner LF, Sloan JA, Venkatesh P. The Control Preferences Scale. Can J Nurs Res. 1997;29:21-43. 
[18] Holmes-Rovner M, Kroll J, Schmitt N, Rovner DR, Breer ML, Rothert ML, et al. Patient satisfaction with health care decisions: the satisfaction with decision scale. Med Decis Making. 1996;16:58-64.

[19] Brehaut JC, O'Connor AM, Wood TJ, Hack TF, Siminoff L, Gordon E, et al. Validation of a decision regret scale. Med Decis Making. 2003;23:281-92.

[20] Wei JT, Dunn RL, Litwin MS, Sandler HM, Sanda MG. Development and validation of the expanded prostate cancer index composite (EPIC) for comprehensive assessment of health-related quality of life in men with prostate cancer. Urology. 2000;56:899-905.

[21] Ware JEJ. SF-36 Health Survey Update. Spine. 2000;25:3130-9.

[22] Brazier JE, Harper R, Jones NM, O'Cathain A, Thomas KJ, Usherwood T, et al. Validating the SF-36 health survey questionnaire: new outcome measure for primary care. BMJ. 1992;305:160-4.

[23] Aizer AA, Paly JJ, Efstathiou JA. Multidisciplinary care and management selection in prostate cancer. Semin Radiat Oncol. 2013;23:157-64.

[24] Aizer AA, Paly JJ, Zietman AL, Nguyen PL, Beard CJ, Rao SK, et al. Multidisciplinary Care and Pursuit of Active Surveillance in Low-Risk Prostate Cancer. J Clin Oncol. 2012;30:3072-76.

[25] Korman H, Lanni T, Jr., Shah C, Parslow J, Tull J, Ghilezan M, et al. Impact of a prostate multidisciplinary clinic program on patient treatment decisions and on adherence to NCCN guidelines: the William Beaumont Hospital experience. Am J Clin Oncol. 2013;36:121-5. doi:

10.1097/COC.0b013e318243708f.

[26] Cooperberg MR, Broering JM, Carroll PR. Time trends and local variation in primary treatment of localized prostate cancer. J Clin Oncol. 2010;28:1117-23. doi: 10.200/JCO.2009.26.0133. Epub 2010 Feb 1.

[27] Moses KA, Paciorek AT, Penson DF, Carroll PR, Master VA. Impact of ethnicity on primary treatment choice and mortality in men with prostate cancer: data from CaPSURE. J Clin Oncol. 2010;28:1069-74. doi: 10.200/JCO.2009.26.469. Epub 10 Jan 25.

[28] Hosain GM, Sanderson M, Du XL, Chan W, Strom SS. Racial/ethnic differences in treatment discussed, preferred, and received for prostate cancer in a tri-ethnic population. Am J Mens Health. 2012;6:249-57.

[29] Mahal BA, Ziehr DR, Aizer AA, Hyatt AS, Lago-Hernandez C, Choueiri TK, et al. Racial disparities in an aging population: The relationship between age and race in the management of African American men with high-risk prostate cancer. J Geriatr Oncol. 2014;23:00069-1.

[30] Mahal BA, Ziehr DR, Aizer AA, Hyatt AS, Sammon JD, Schmid M, et al. Getting back to equal: The influence of insurance status on racial disparities in the treatment of African American men with highrisk prostate cancer. Urol Oncol. 2014;32:1285-91. doi: 10.016/j.urolonc.2014.04.014. Epub May 17. [31] Bureau USC. Current Population Survey, 2014 Annual Social and Economic Supplement. 2014. [32] Weiner AB, Patel SG, Etzioni R, Eggener SE. National trends in the management of low and intermediate risk prostate cancer in the United States. J Urol. 2015;193:95-102. doi:

10.1016/j.juro.2014.07.111. Epub Aug 5.

[33] Filson CP, Schroeck FR, Ye Z, Wei JT, Hollenbeck BK, Miller DC. Variation in Use of Active Surveillance among Men Undergoing Expectant Treatment for Early Stage Prostate Cancer. J Urol. 2014;8:00230-4. 


\section{Figure Legends}

Figure 1: Study schema. Patient enrollment and questionnaire administration for the prospective decision-making and quality of life studies are displayed below. The two studies are distinct, but the majority of patients are dually enrolled. EPIC=Expanded Prostate Cancer Index Composite, SF36=RAND Medical Outcomes Study Short Form.

Figure 2: Control preferences scale. Prior to attending the multidisciplinary clinic, patients were asked "Which statement best describes your preferences about the doctor's role in the treatment decision for your prostate cancer?" Responses indicate a desire to play either an active (A\&B), collaborative (C), or passive (D\&E) role in treatment decision-making.

Figure 3: Thoughts on treatment before and after attending the multidisciplinary clinic. Prior to attending the multidisciplinary clinic, the majority of patients were unsure about most treatment options. After attending the clinic, the percent of patients unsure about each treatment decreased sharply, while the percent of patients leaning strongly towards or against each treatment rose. RP=Radical Prostatectomy, EBRT=External Beam Radiation Therapy, Brachy=Brachytherapy, HT=Hormone Therapy, AS/WW=Active Surveillance/Watchful Waiting.

Color printing is required for figures $2 \& 3$. 
Tables

Table 1: Demographic Characteristics ( $\mathrm{N}=925)$

\section{Age at Diagnosis}

Mean (SD)

61

(9)

Race/Ethnicity (N (\%))

African-American

336

Caucasian

547

Hispanic

28

Asian

8

Other/Missing

6

Branch Of Service (N (\%))

Air Force

Army

454

Coast Guard

20

Marines

42

Navy

164

Other

24

Military Status (N (\%))

Active duty

136

Dependent

27

Retired

762

Marital Status (N (\%))

Married

794

Not Married

130

Education (N (\%))

High School/GED

148

Associate/Baccalaureate Degree

294

Masters/Doctoral Degree

480

Family History of CaP (N (\%))

No

398

Yes

324

Unknown

203 
Table 2: Clinical Characteristics ( $\mathbf{N}=925)$

PSA at diagnosis (ng/mL)

Mean (SD)

$6.6 \quad(9.3)$

Clinical Stage (N (\%))

cT1

$689 \quad(75)$

cT2

231

cT3

5

(1)

Gleason Sum (N (\%))

$<=6$

$585 \quad(63)$

7

255

8-10

85

(9)

NCCN Risk Stratum (N (\%))

Very Low/Low

$539 \quad(58)$

Intermediate

286

High

100

(11)

Major Comorbidity ${ }^{*}$ (N (\%))

Yes

$153 \quad(17)$

No

757

Missing

15

(2)

PSA=Prostate specific antigen, $\mathrm{NCCN}=$ National Comprehensive Cancer Network

*History of heart disease/CAD, lung disease/COPD, and/or stroke 
Table 3: Primary Treatment Received, Overall and by NCCN Risk Stratum

\begin{tabular}{lllllllll}
\hline & \multicolumn{2}{l}{ Overall } & \multicolumn{3}{c}{ Very Low/ Low } & \multicolumn{2}{c}{ Intermediate } & High \\
& $\mathbf{N}$ & $\mathbf{\%}$ & $\mathbf{N}$ & $\mathbf{\%}$ & $\mathbf{N}$ & $\mathbf{\%}$ & $\mathbf{N}$ & \% \\
\hline Radical Prostatectomy & 476 & $(51)$ & 282 & $(52)$ & 160 & $(56)$ & 34 & $(34)$ \\
EBRT & 163 & $(18)$ & 90 & $(17)$ & 73 & $(26)$ & 0 & $(0)$ \\
NHT/EBRT & 75 & $(8)$ & 1 & $(0)$ & 17 & $(6)$ & 57 & $(57)$ \\
EBRT/Brachytherapy & 5 & $(1)$ & 0 & $(0)$ & 4 & $(1)$ & 1 & $(1)$ \\
Brachytherapy & 51 & $(6)$ & 47 & $(9)$ & 4 & $(1)$ & 0 & $(0)$ \\
Hormone Therapy & 4 & $(0)$ & 0 & $(0)$ & 1 & $(0)$ & 3 & $(3)$ \\
Active Surveillance & 98 & $(11)$ & 86 & $(16)$ & 12 & $(4)$ & 0 & $(0)$ \\
Watchful Waiting & 8 & $(1)$ & 6 & $(1)$ & 1 & $(0)$ & 1 & $(1)$ \\
Cyberknife & 6 & $(1)$ & 3 & $(1)$ & 3 & $(1)$ & 0 & $(0)$ \\
HIFU & 3 & $(0)$ & 3 & $(1)$ & 0 & $(0)$ & 0 & $(0)$ \\
Proton Beam Therapy & 7 & $(1)$ & 2 & $(0)$ & 4 & $(1)$ & 1 & $(1)$ \\
Other* & (3) & 19 & $(4)$ & 7 & $(2)$ & 3 & $(3)$ \\
\hline
\end{tabular}


Table 4: Comparison of Sociodemographic Factors Among Low- and Intermediate-Risk Patients Undergoing Radical Prostatectomy (RP), External Beam Radiation Therapy (EBRT), or Active Surveillance (AS)

\begin{tabular}{|c|c|c|c|c|c|}
\hline & $\begin{array}{l}\text { RP } \\
(\mathrm{N}=442)\end{array}$ & $\begin{array}{l}\text { EBRT } \\
(N=163)\end{array}$ & $\begin{array}{l}\text { AS } \\
(\mathrm{N}=98)\end{array}$ & $\begin{array}{l}p \text {-value } \\
\text { (unadjusted) }\end{array}$ & $\begin{array}{l}p \text {-value } \\
\text { (adjusted) }\end{array}$ \\
\hline \multicolumn{6}{|l|}{ Age at Diagnosis } \\
\hline Mean (SD) & $58(7)$ & $66(9)$ & $62(8)$ & $<\mathbf{0 . 0 0 0 1}^{\mathrm{abc}}$ & $<0.0001^{\mathrm{ab}}$ \\
\hline \multicolumn{6}{|l|}{ Race (N (\%)) } \\
\hline African-American & $136(55)$ & $86(35)$ & $27(11)$ & $<0.0001^{\text {ac }}$ & $<0.0001^{\mathrm{ac}}$ \\
\hline Caucasian & $283(68)$ & $71(17)$ & $65(16)$ & & \\
\hline Other & $23(66)$ & $6 \quad(17)$ & $6 \quad(17)$ & & \\
\hline \multicolumn{6}{|l|}{ Marital Status (N (\%)) } \\
\hline Married & $385(62)$ & $145(23)$ & $88(14)$ & 0.6818 & 0.1647 \\
\hline Not Married & $57 \quad(67)$ & $18(21)$ & $10(12)$ & & \\
\hline \multicolumn{6}{|l|}{ Education (N (\%)) } \\
\hline High School/GED & $57 \quad(56)$ & $32(32)$ & $12(12)$ & 0.2001 & 0.8233 \\
\hline Assc/Bacc Degree & $142(64)$ & $52(23)$ & $28(13)$ & & \\
\hline Masters/Doctoral Degree & $243(64)$ & $78(21)$ & $57(15)$ & & \\
\hline \multicolumn{6}{|l|}{ Family History (N (\%)) } \\
\hline Yes & $186(71)$ & $45(17)$ & $30(11)$ & $0.0035^{\mathrm{a}}$ & $0.0582^{\mathrm{b}}$ \\
\hline No & $165(56)$ & $80(27)$ & $51(17)$ & & \\
\hline Unknown & $91 \quad(62)$ & $38(26)$ & 17 (12) & & \\
\hline \multicolumn{6}{|c|}{ Major Comorbidity (N (\%)) } \\
\hline Yes & $38 \quad(40)$ & $39(41)$ & 18 (19) & $<0.0001^{a b}$ & $0.0171^{\mathrm{a}}$ \\
\hline No & $400(67)$ & $117(20)$ & $78(13)$ & & \\
\hline \multicolumn{6}{|l|}{ Calendar Year (N (\%)) } \\
\hline $2006-2008$ & $206(68)$ & $77(26)$ & $18(6)$ & $<0.0001^{b c}$ & $<0.0001^{\text {bc }}$ \\
\hline 2009-2011 & $185(64)$ & $58(20)$ & $44(15)$ & & \\
\hline 2012-2014 & $51 \quad(44)$ & $28(24)$ & $36(31)$ & & \\
\hline $\begin{array}{l}\text { "Adjusted for all other var } \\
\text { a Significant difference bet } \\
{ }^{\mathrm{b}} \text { Significant difference bet } \\
{ }^{\mathrm{c}} \text { Significant difference bet }\end{array}$ & $\begin{array}{l}\text { in table anc } \\
\text { RP and EB } \\
\text { RP and AS } \\
\text { EBRT and }\end{array}$ & $\mathrm{N}$ risk strat & & & \\
\hline
\end{tabular}


Table 5: Comparison of Sociodemographic Factors Among High-Risk Patients Undergoing Radical Prostatectomy (RP) or External Beam Radiation Therapy with Neo-adjuvant Hormones (NHT/EBRT)

\begin{tabular}{|c|c|c|c|c|}
\hline & $\begin{array}{l}\mathbf{R P} \\
(\mathrm{N}=34)\end{array}$ & $\begin{array}{l}\text { NHT/EBRT } \\
(\mathrm{N}=57)\end{array}$ & $\begin{array}{l}p \text {-value } \\
\text { (unadjusted) }\end{array}$ & $\begin{array}{l}p \text {-value } \\
\text { (adjusted) }\end{array}$ \\
\hline \multicolumn{5}{|l|}{ Age at Diagnosis } \\
\hline Mean (SD) & $59(6)$ & $70(8)$ & $<0.0001$ & $<0.0001$ \\
\hline \multicolumn{5}{|l|}{$\operatorname{Race}(\mathbf{N}(\%))$} \\
\hline African-American/Other & $13(33)$ & $27(68)$ & 0.3100 & 0.8944 \\
\hline Caucasian & $21(41)$ & $30(59)$ & & \\
\hline \multicolumn{5}{|l|}{ Marital Status (N (\%)) } \\
\hline Married & $30(39)$ & $47(61)$ & 0.4598 & 0.4408 \\
\hline Not Married & $4(29)$ & $10(71)$ & & \\
\hline \multicolumn{5}{|l|}{ Education (N (\%)) } \\
\hline High School/GED & $4(17)$ & $20(83)$ & 0.0125 & 0.0496 \\
\hline Assc/Bacc Degree & $11(39)$ & $17(61)$ & & \\
\hline Masters/Doctoral Degree & $19(49)$ & $20(51)$ & & \\
\hline \multicolumn{5}{|l|}{ Family History (N (\%)) } \\
\hline Yes & $9(36)$ & $16(64)$ & 0.8351 & 0.5980 \\
\hline No & $17(40)$ & $25(60)$ & & \\
\hline Unknown & $8(33)$ & $16(67)$ & & \\
\hline \multicolumn{5}{|c|}{ Major Comorbidity (N (\%)) } \\
\hline Yes & $5(15)$ & $28(85)$ & 0.0008 & 0.1745 \\
\hline No & $29(51)$ & $28(49)$ & & \\
\hline \multicolumn{5}{|l|}{ Calendar Year (N (\%)) } \\
\hline 2006-2008 & $18(47)$ & $20(53)$ & 0.1926 & 0.3954 \\
\hline 2009-2011 & $10(29)$ & $25(71)$ & & \\
\hline 2012-2014 & $6(33)$ & $12(67)$ & & \\
\hline
\end{tabular}


Table 6: What source(s) of information helped you the most to make your treatment decision?

\begin{tabular}{ll}
\hline Information from a doctor(s) I saw at the CPDR & $87 \%$ \\
Information from reading materials (books, pamphlets, magazines, newspapers, etc.) & $40 \%$ \\
Comments from my wife or significant other & $33 \%$ \\
Information from the Internet & $30 \%$ \\
Information from (or about) a family member or acquaintance with prostate cancer & $28 \%$ \\
Information from a doctor(s) not at the CPDR & $27 \%$ \\
Other & $6 \%$ \\
Information from a prostate cancer support group & $5 \%$ \\
Information from the media about a person with prostate cancer & $5 \%$ \\
Spiritual/religious beliefs or practices & $4 \%$ \\
\hline
\end{tabular}


DECISION-MAKING STUDY

QUALITY OF LIFE STUDY

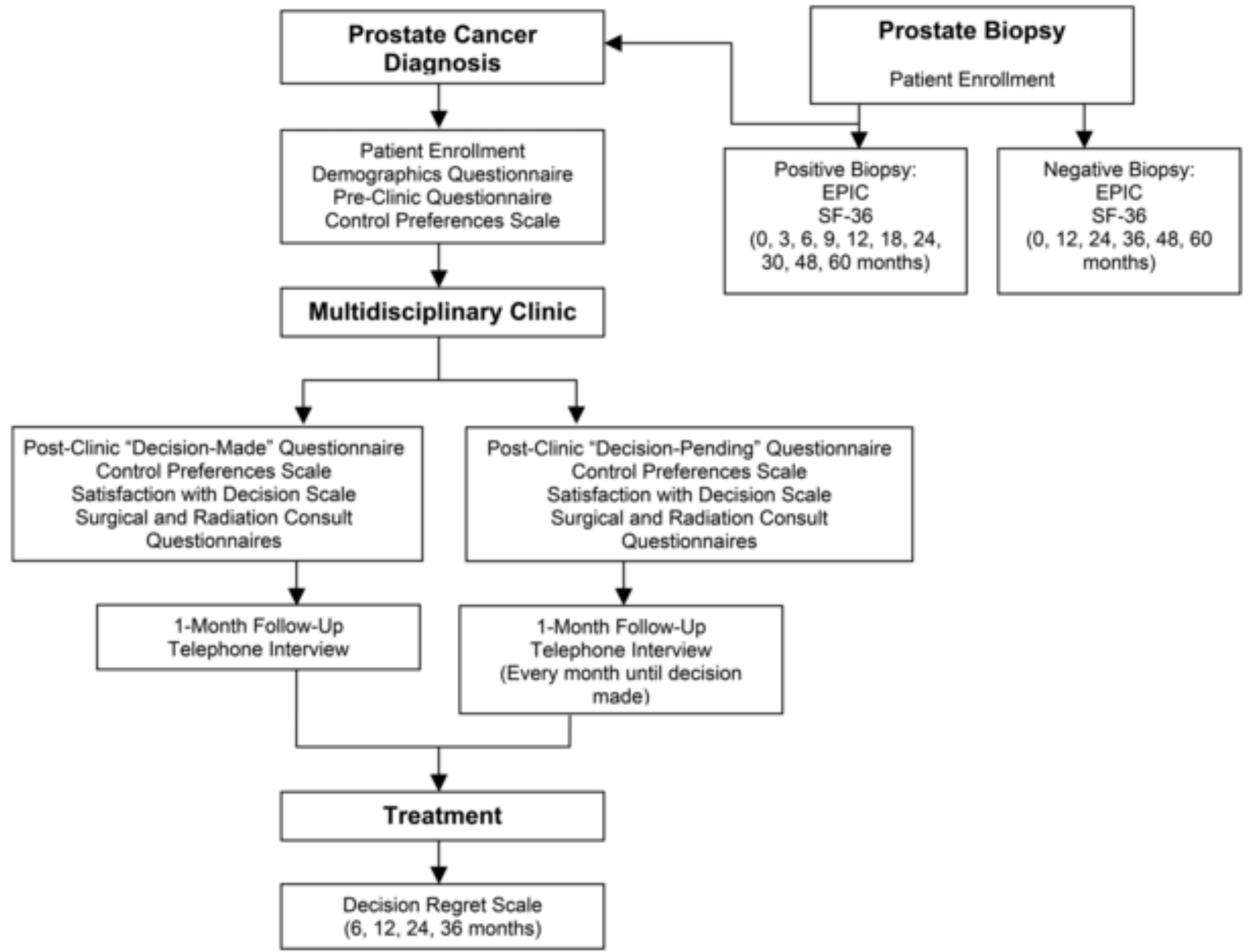




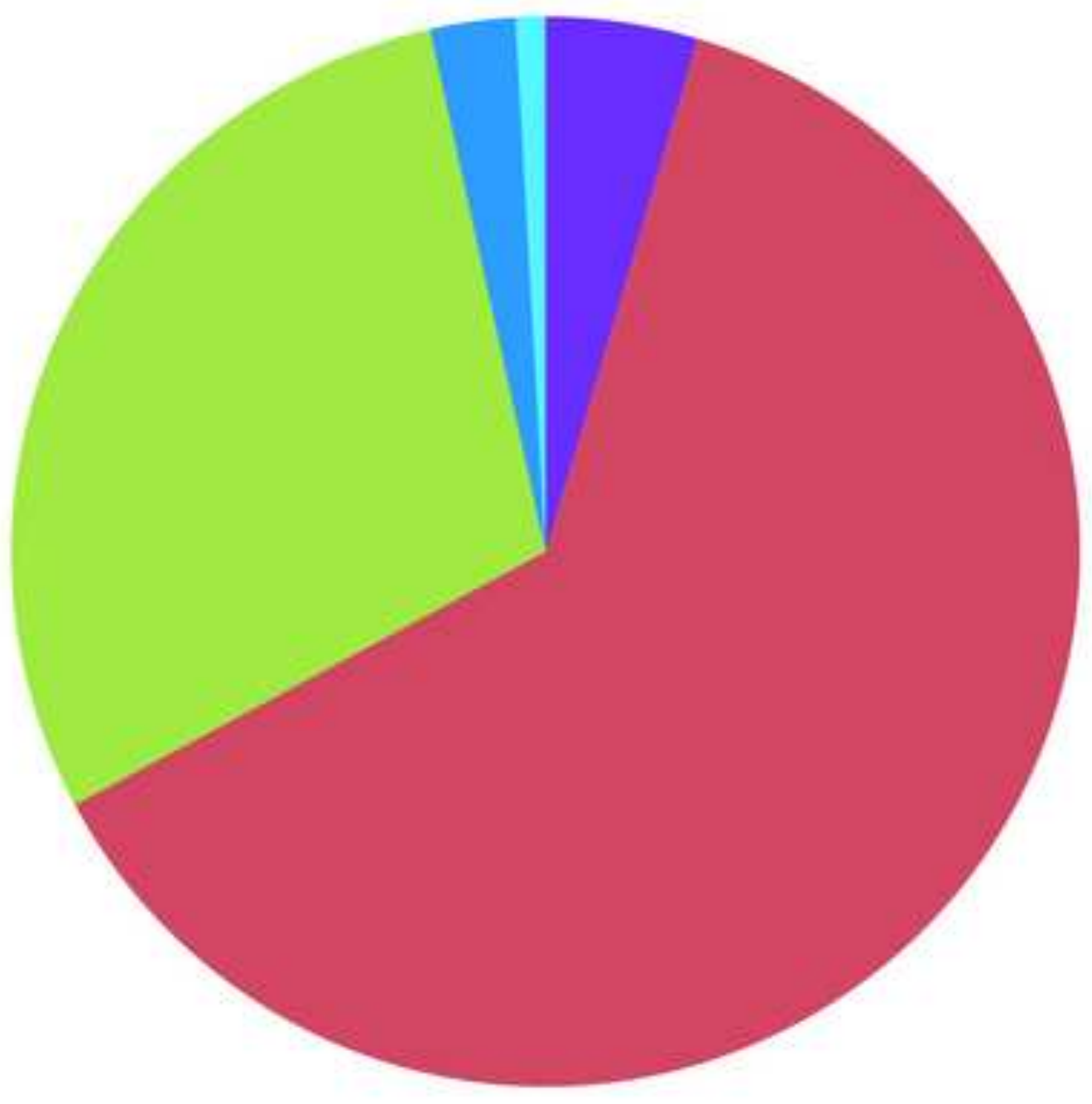

in A. I prefer to make the final selection $(5 \%)$

B. I prefer to make the final selection after seriously considering my doctor's opinion (63\%)

- C. I prefer that my doctor and I share responsibility $(29 \%)$

D. I prefer that my doctor make the final decision, but seriously considers my opinion (3\%)

E. I prefer to leave all decisions regarding my treatment to my doctor $(1 \%)$ 
Which of the following statements best describe your thinking at the present time about your treatment decision for prostate cancer? $(\mathrm{N}=925)$

\section{Pre-Clinic}

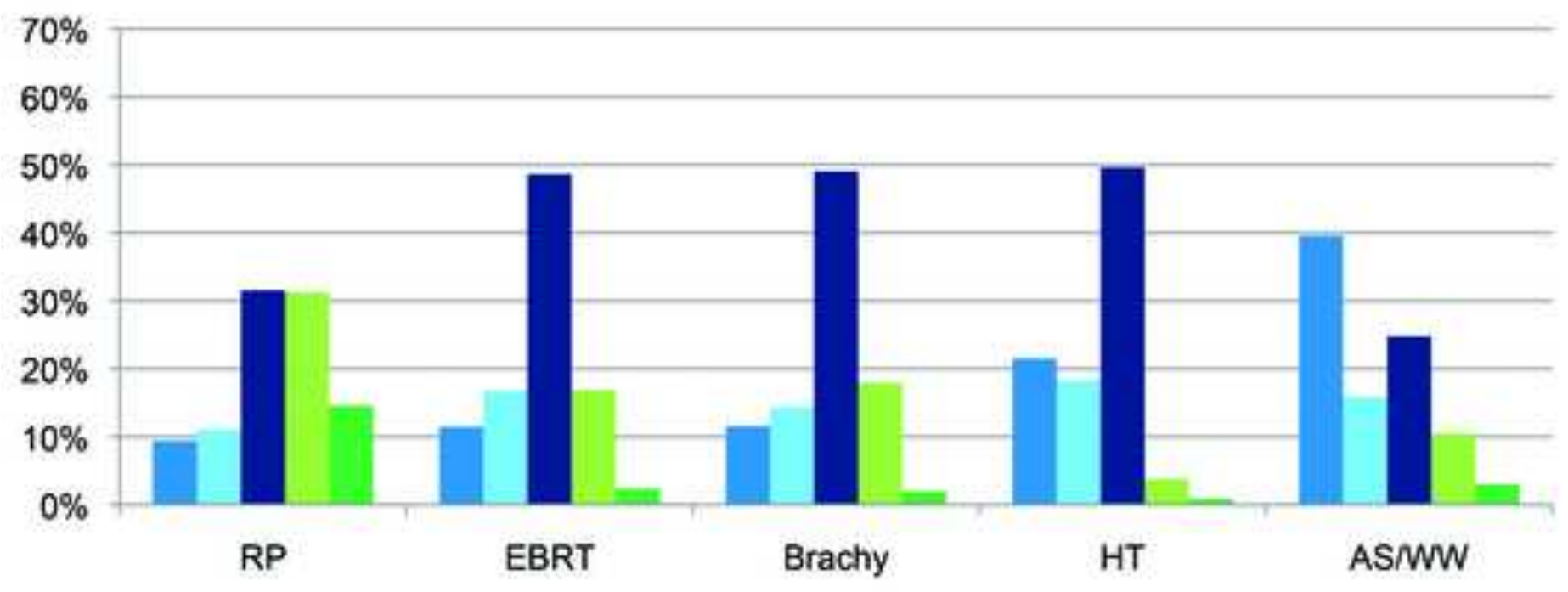

Post-Clinic

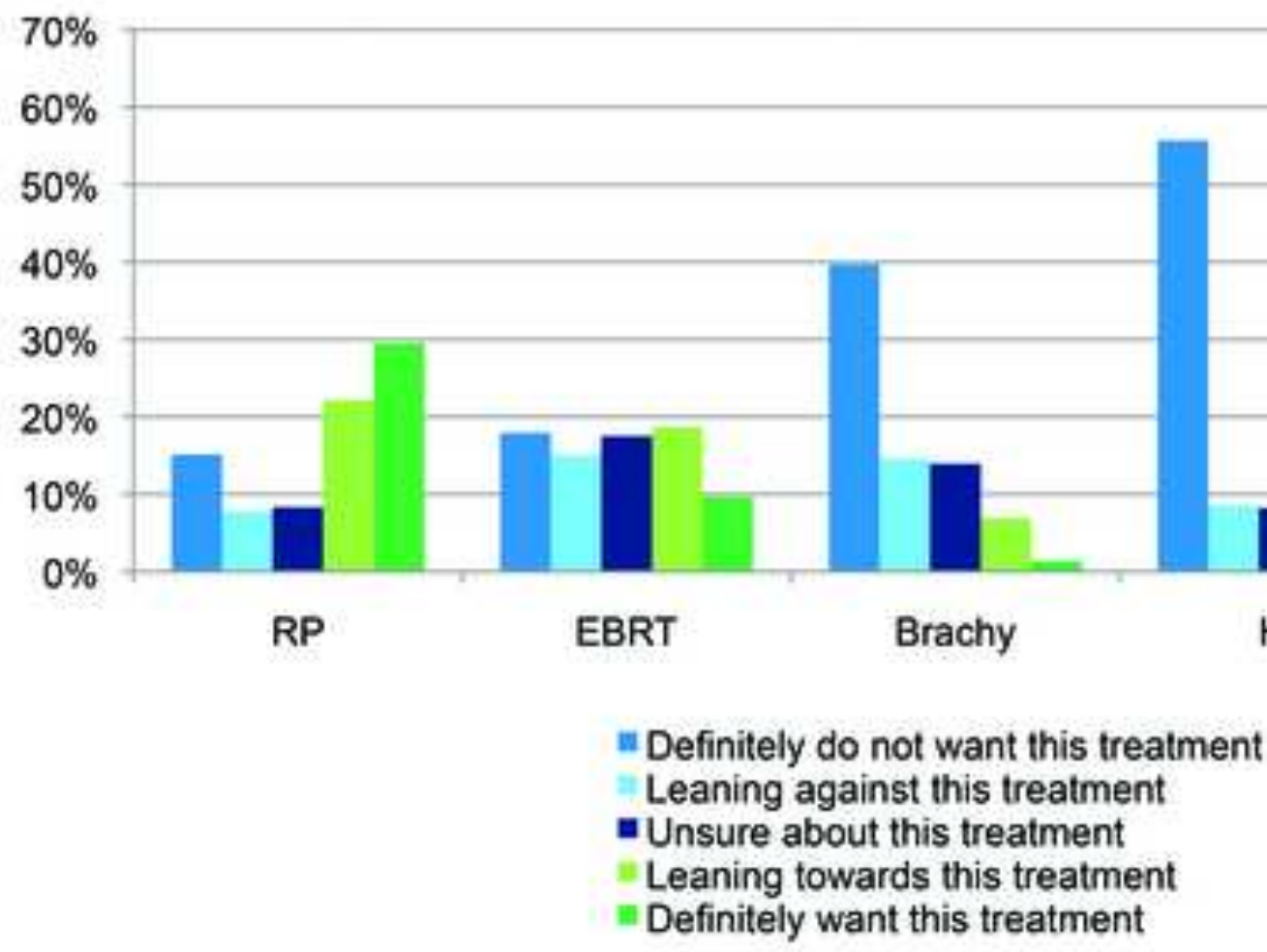

